\title{
Bone - a casualty of ICU survival?
}

\author{
Karin Amrein*, Astrid Fahrleitner-Pammer and Hans Peter Dimai \\ See related research by Rawal et al., http://ccforum.com/content/19/1/165
}

We read with great interest the pilot study on fracture risk in 46 critically ill patients by Rawal and colleagues [1]. Bone mineral density (BMD) was assessed with portable calcaneal dual X-ray absorptiometry (DXA) on days 1 and 10. The authors found no overall change in BMD, but increased fracture risk in the subgroup with 'ARDS' (acute respiratory distress syndrome) $(\mathrm{n}=34)$. There are several serious methodological problems: it is unclear if the group assignment is valid as only one of the four Berlin definition criteria [2] for the diagnosis of ARDS is given: oxygenation (no information on timing, chest imaging and origin of the edema). Although peripheral DXA devices are certainly an interesting option for BMD in critically ill and other patients [3], precision errors supplied by the manufacturer should not be used. In fact, each center must determine its (own) precision error and least significant change, which is also operator dependent [4]. The manufacturer stated a $0.9 \%$ coefficient of variation, which is not necessarily applicable to the study setting where it remains unclear how the measurements were performed. This could be an important limitation. Hence, it is unlikely that a $2 \%$ BMD change within such a short time frame as described would reflect anything else other than random variability. Lastly, it is also unclear what the described statistical difference refers to - it should be noted that the smaller subgroup $(\mathrm{n}=12)$ numerically increased their BMD. Undoubtedly, fracture risk following critical illness is a very important topic that requires further high-quality studies [5].

\section{Competing interests}

The authors declare that they have no competing interests.

Authors' information

HPD is Vice Rector for Teaching and Studies at the Medical University of Graz.

Published online: 18 June 2015

\section{References}

1. Rawal J, McPhail MJ, Ratnayake G, Chan P, Moxham J, Harridge SD, et al. A pilot study of change in fracture risk in patients with acute respiratory distress syndrome. Crit Care. 2015;19:165.

2. Ranieri VM, Rubenfeld GD, Thompson BT, Ferguson ND, Caldwell E, Fan E, et al. Acute respiratory distress syndrome: the Berlin Definition. JAMA. 2012;307:2526-33.

3. Muschitz C, Dimai HP, Kocijan R, Kaider A, Zendeli A, Kuhne F, et al. The discriminatory capacity of BMD measurements by DXA and dual X-ray and laser (DXL) at the calcaneus including clinical risk factors for detecting patients with vertebral fractures. Osteoporos Int. 2013;24:2181-90.

4. Schousboe JT, Shepherd JA, Bilezikian JP, Baim S. Executive summary of the 2013 International Society for Clinical Densitometry Position Development Conference on bone densitometry. J Clin Densitom. 2013;16:455-66.

5. Griffith DM, Walsh TS. Bone loss during critical illness: a skeleton in the closet for the intensive care unit survivor? Crit Care Med. 2011;39:1554-6.

\section{Abbreviations}

ARDS: Acute respiratory distress syndrome; BMD: Bone mineral density;

DXA: Dual energy X-ray absorptiometry.

\footnotetext{
* Correspondence: karin.amrein@medunigraz.at

Department of Internal Medicine, Division of Endocrinology and Metabolism, Medical University of Graz, Auenbruggerplatz 15, A-8036 Graz, Austria
} 